\title{
Natural Language Processing of Clinical Notes on Chronic Diseases: Systematic Review
}

Seyedmostafa Sheikhalishahi ${ }^{1,2}$, MSc; Riccardo Miotto $^{3}, \mathrm{PhD}$; Joel T Dudley ${ }^{3}$, PhD; Alberto Lavelli ${ }^{4}$, MSc; Fabio Rinaldi $^{5}, \mathrm{PhD}$; Venet Osmani ${ }^{1}, \mathrm{PhD}$

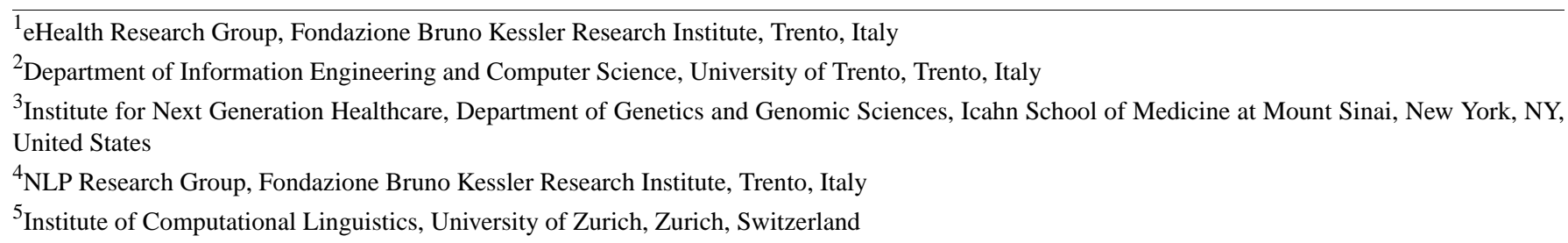

Corresponding Author:

Venet Osmani, PhD

eHealth Research Group

Fondazione Bruno Kessler Research Institute

Via Sommarive 18, Povo

Trento, 38123

Italy

Phone: 390461312479

Email: vosmani@ fbk.eu

\begin{abstract}
Background: Novel approaches that complement and go beyond evidence-based medicine are required in the domain of chronic diseases, given the growing incidence of such conditions on the worldwide population. A promising avenue is the secondary use of electronic health records (EHRs), where patient data are analyzed to conduct clinical and translational research. Methods based on machine learning to process EHRs are resulting in improved understanding of patient clinical trajectories and chronic disease risk prediction, creating a unique opportunity to derive previously unknown clinical insights. However, a wealth of clinical histories remains locked behind clinical narratives in free-form text. Consequently, unlocking the full potential of EHR data is contingent on the development of natural language processing (NLP) methods to automatically transform clinical text into structured clinical data that can guide clinical decisions and potentially delay or prevent disease onset.
\end{abstract}

Objective: The goal of the research was to provide a comprehensive overview of the development and uptake of NLP methods applied to free-text clinical notes related to chronic diseases, including the investigation of challenges faced by NLP methodologies in understanding clinical narratives.

Methods: Preferred Reporting Items for Systematic Reviews and Meta-Analyses (PRISMA) guidelines were followed and searches were conducted in 5 databases using "clinical notes," "natural language processing," and "chronic disease" and their variations as keywords to maximize coverage of the articles.

Results: Of the 2652 articles considered, 106 met the inclusion criteria. Review of the included papers resulted in identification of 43 chronic diseases, which were then further classified into 10 disease categories using the International Classification of Diseases, 10th Revision. The majority of studies focused on diseases of the circulatory system $(\mathrm{n}=38)$ while endocrine and metabolic diseases were fewest $(\mathrm{n}=14)$. This was due to the structure of clinical records related to metabolic diseases, which typically contain much more structured data, compared with medical records for diseases of the circulatory system, which focus more on unstructured data and consequently have seen a stronger focus of NLP. The review has shown that there is a significant increase in the use of machine learning methods compared to rule-based approaches; however, deep learning methods remain emergent $(n=3)$. Consequently, the majority of works focus on classification of disease phenotype with only a handful of papers addressing extraction of comorbidities from the free text or integration of clinical notes with structured data. There is a notable use of relatively simple methods, such as shallow classifiers (or combination with rule-based methods), due to the interpretability of predictions, which still represents a significant issue for more complex methods. Finally, scarcity of publicly available data 
may also have contributed to insufficient development of more advanced methods, such as extraction of word embeddings from clinical notes.

Conclusions: Efforts are still required to improve (1) progression of clinical NLP methods from extraction toward understanding; (2) recognition of relations among entities rather than entities in isolation; (3) temporal extraction to understand past, current, and future clinical events; (4) exploitation of alternative sources of clinical knowledge; and (5) availability of large-scale, de-identified clinical corpora.

(JMIR Med Inform 2019;7(2):e12239) doi: 10.2196/12239

\section{KEYWORDS}

electronic health records; clinical notes; chronic diseases; natural language processing; machine learning; deep learning; heart disease; stroke; cancer; diabetes; lung disease

\section{Introduction}

\section{Overview}

The burden of chronic diseases, such as cancers, diabetes, and hypertension, is widely accepted as one of the principal challenges of health care. While immense progress has been made in the discovery of new treatments and prevention strategies, this challenge not only persists, but its incidence is exhibiting an upward trend [1], with significant impact on patient quality of life and care costs. Consequently, there is a need for novel approaches to complement and go beyond current evidence-based medicine that can reduce the impact of chronic conditions on modern society.

A promising direction is the secondary use of electronic health records (EHRs) to analyze patient data, advance medical research, and better inform clinical decision making. Methods based in analysis of EHRs [2] are resulting in improved understanding of patient clinical trajectories [3] while enabling better patient stratification and risk prediction [4-6]. In particular, use of machine learning and especially deep learning to process EHRs is creating a unique opportunity to derive previously unknown clinical insights [7]. This is especially relevant for chronic diseases as their longitudinal nature provides a very large and continuous stream of data, where clinically meaningful patterns can be extracted and used to guide clinical decisions, including delaying or preventing disease onset.

However, EHRs are challenging to represent and model due to their high dimensionality, noise, heterogeneity, sparseness, incompleteness, random errors, and systematic biases. Moreover, a wealth of information about patient clinical history is generally locked behind free-text clinical narratives [8] since writing text remains the most natural and expressive method to document clinical events. Development of natural language processing (NLP) methods is essential to automatically transform clinical text into structured clinical data that can be directly processed using machine learning algorithms. Use of NLP in the clinical domain is seeing an increasing uptake with diverse applications, including identification of biomedical concepts from radiology reports [9], nursing documentation [10], and discharge summaries [11]. Frameworks based on NLP applied to clinical narratives, however, have not been widely used in clinical settings to help decision support systems or workflows.

\section{Motivation}

Clinically relevant information from clinical notes has been historically extracted via manual review by clinical experts, leading to scalability and cost issues. This is of particular relevance for chronic diseases since clinical notes dominate over structured data (for example, Wei et al [12] graphically quantify the amount of clinical notes over structured data for chronic diseases such as rheumatoid arthritis, Parkinson disease, and Alzheimer disease). Availability of these data creates an immense opportunity for NLP to automatically extract clinically meaningful information that may delay or prevent disease onset, giving rise, however, to several challenges. In this paper we aimed to identify directions that could speed up the adoption of NLP of clinical notes for chronic diseases and provide an understanding of the current challenges and state of the art.

Systematic reviews related to processing of clinical notes have been published in the past [13-18]; however, none have focused specifically on chronic diseases, making it difficult to derive conclusions and recommendations on this specific and very diverse domain. In particular, this paper investigates NLP challenges related to 43 unique chronic diseases identified by our systematic review and discusses the trends of applying various NLP methods for clinical translational research. Based on the outcomes of this review, we also devised a number of recommendations on future research directions, including (1) evolution of clinical NLP methods from extraction toward understanding; (2) recognition of relations among entities, rather than entities in isolation; (3) temporal extraction in order to understand past, current, and future clinical events; (4) exploitation of alternative sources of clinical knowledge; and (5) availability of large-scale deidentified and annotated clinical corpora.

\section{Methods}

\section{Search Strategy and Information Sources}

We followed the Preferred Reporting Items for Systematic Reviews and Meta-Analyses (PRISMA) guidelines [19]. We carried out a search of several databases to identify all potentially relevant articles published from January 1, 2007, to February 6, 2018, including Scopus, Web of Science (including MEDLINE) and PubMed, and the Association for Computing Machinery (ACM) Digital Library. We have limited the search to journal articles written in English. In all the searches we used the combination of the following groups of keywords: (1) 
"clinical notes," "medical notes," or "clinical narratives"; (2) "natural language processing," "medical language processing," "text mining," or "information extraction"; and (3) "chronic disease," "heart disease," "stroke," "cancer," "diabetes," or "lung disease" (where the last set of keywords reflects the top five chronic diseases). The search keywords were selected to be exhaustive to maximize coverage of the articles. The exact queries are provided in Multimedia Appendix 1.

\section{Article Selection}

In the initial queries we also included the following terms: "electronic health records," "EHR," "electronic medical records," and "EMR." This led to a total of 2652 retrieved articles. However, upon reviewing these articles, we noticed that the scope was too broad, providing results outside of focus of this review. Consequently, we narrowed the search strategy to the keywords specified in the previous section, obtaining a total of 478 articles, with 401 articles from Scopus, 58 from Web of Science (including PubMed), 13 from ACM Digital Library, and 6 added manually, including 4 conference papers. After removing 46 duplicates, 432 articles were retained, and two authors (MS and VO) reviewed their titles and abstracts (216 articles each). After this screening phase, 159 articles were retained for further analysis.

In the second screening stage, five authors independently reviewed the 159 full-text articles, resulting in 106 articles fulfilling our criteria that are discussed in this review. The most common reason for exclusion was that the work was not directly related to chronic diseases $(n=32)$; another reason was the work was not topical (eg, the article was not a journal paper or we could not retrieve the text). A flowchart and description of the selection process are provided in Figure 1 and Multimedia Appendix 2, respectively.

Figure 1. Preferred Reporting Items for Systematic Reviews and Meta-Analyses article selection flowchart. ACM: Association for Computing Machinery; NLP: natural language processing.
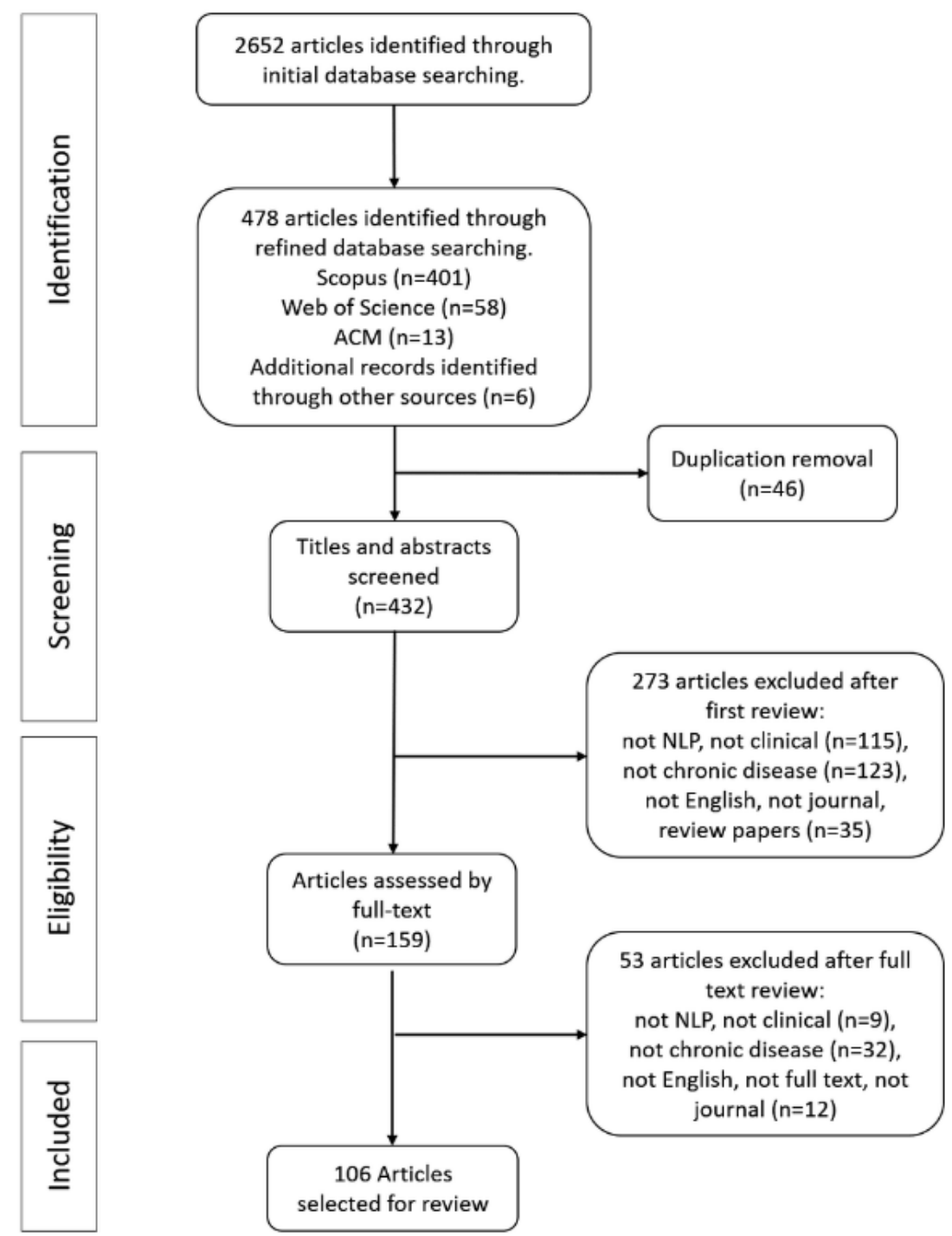


\section{Results}

\section{Categorization of Diseases}

The 106 articles reviewed were largely related to 43 unique chronic diseases (as shown in Multimedia Appendix 2). One of our aims was to understand the extent of NLP for specific disease categories and their associated clinical notes. Therefore, we grouped the 43 unique chronic diseases into 10 disease categories using the International Classification of Diseases, 10th Revision (ICD-10) as shown in Table 1.

Table 1. Classifications of chronic conditions studied $(\mathrm{n}=102)$ and the corresponding number of papers found.

\begin{tabular}{|c|c|c|}
\hline Classification of chronic condition & Studies, n $(\%)$ & Conditions included \\
\hline Diseases of the circulatory system & $38(35.8)$ & $\begin{array}{l}\text { Congestive heart disease (2), coronary artery disease (6), heart disease (6), heart failure (7), } \\
\text { hypertension (5), peripheral arterial disease (3), pulmonary disease (4) }\end{array}$ \\
\hline Neoplasms & $34(32.1)$ & Breast cancer (8), colorectal cancer (7), prostate cancer (4), lymphoma (2) \\
\hline $\begin{array}{l}\text { Endocrine, nutritional, and } \\
\text { metabolic diseases }\end{array}$ & $14(13.2)$ & Type 2 diabetes mellitus (12), obesity (2) \\
\hline Other diseases & $16(15.1)$ & $\begin{array}{l}\text { Diseases of the digestive system (3), diseases of the genitourinary system (3), diseases of the } \\
\text { musculoskeletal system and connective tissue (3), diseases of the respiratory system (2), } \\
\text { mental and behavioral disorders (2), multidisease (3) }\end{array}$ \\
\hline
\end{tabular}

Figure 2. Relationship between chronic diseases (black sectors) and articles included in the review (for clarity we have included only diseases that are addressed by three or more articles).

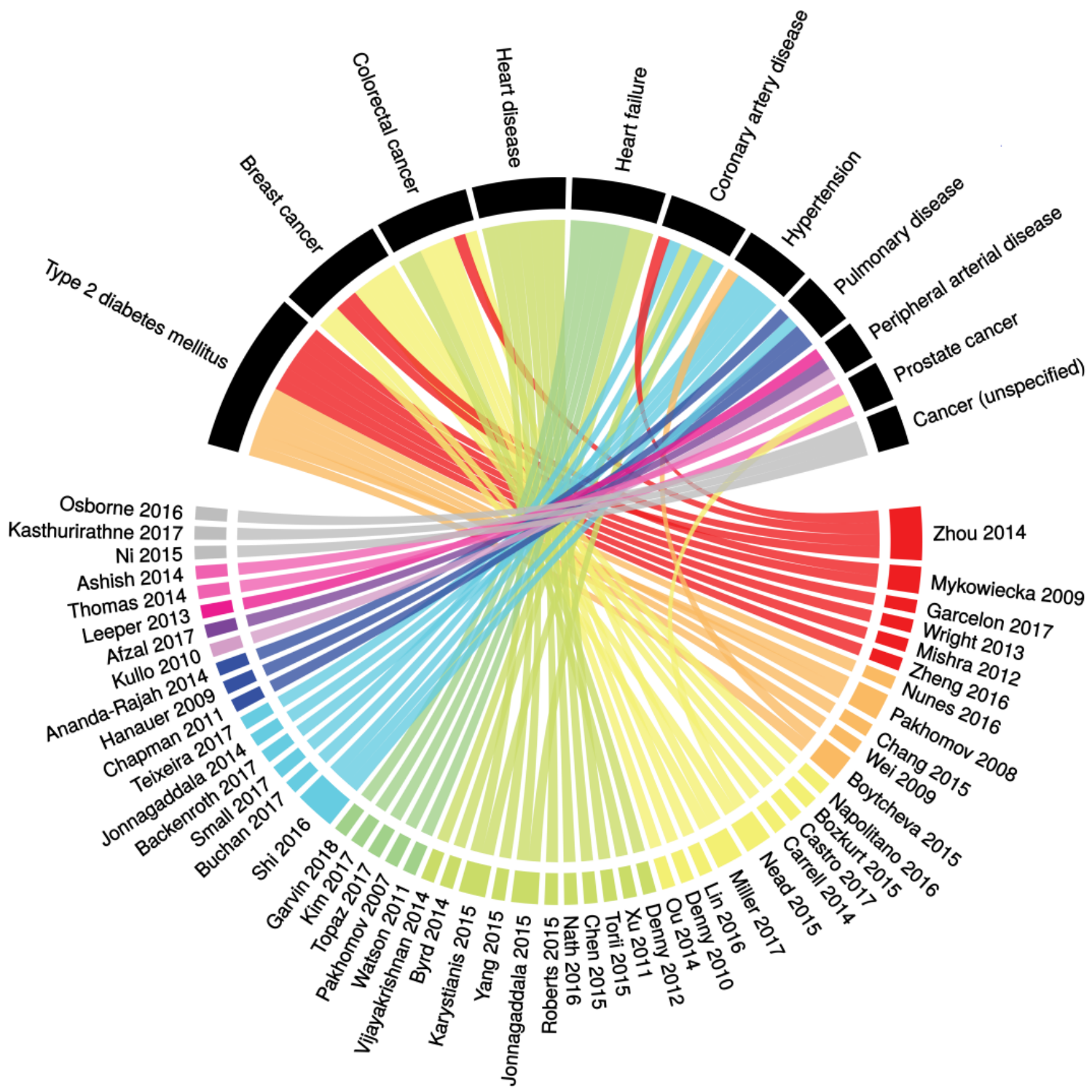


The top three disease groups were (1) diseases of the circulatory system $(n=38)$ (such as coronary artery disease [20] and hypertension [21]); (2) neoplasms $(n=34)$ (such as breast cancer [22] and prostate cancer [23]); and (3) endocrine, nutritional, and metabolic diseases $(n=14)$ (such as type 2 diabetes [24] and obesity [25]). An overview of the diseases studied and the corresponding articles is shown in Figure 2.

An unexpected finding is that despite the higher incidence of metabolic diseases in the general population [26] compared with diseases of circulatory system [27], the use of NLP in clinical narratives of these diseases exhibits an opposite trend. Diseases of the circulatory system are represented in much greater numbers with respect to metabolic diseases $(n=38$ vs $\mathrm{n}=14$, respectively). We hypothesize that the structure of data contained in EHRs may explain this finding. Medical records related to metabolic diseases typically contain much more structured data (for example, numerical values for various physiological and physical parameters) than medical records for diseases of the circulatory system, which focus more on unstructured data [28]. This creates a more pressing need to use NLP to extract information from notes related to diseases of the circulatory system, whereas EHRs of patients with metabolic diseases in large part may already contain data that can be used by algorithms with minimal preprocessing. In the sections that follow we summarize the most representative papers (the complete list is provided in Multimedia Appendix 2).

\section{Disease Groups}

\section{Diseases of the Circulatory System}

\section{Cardiovascular Diseases}

Most of the work in this area focused on using NLP to estimate the risk of heart disease. As an example, Chen et al [29] developed a hybrid pipeline based on both machine learning and rules to identify medically relevant information related to heart disease risk and track the disease progression over sets of longitudinal patient records, including clinical notes (similarly to Torri et al [30]). Karystianis et al [31] and Yang et al [32] evaluated the identification of heart disease risk factors from the clinical notes of diabetic patients. In a slightly different approach, Roberts et al [33] focused on estimating heart disease risk based on classification of 8 risk triggers (for example, aspirin). Other studies in this area have focused on evaluating the use of aspirin as a risk factor [34,35], extracting heart function measurements from echocardiograms [36], deep vein thrombosis and pulmonary embolism [37], and low-density lipoprotein level and statins use [38].

Risk of stroke and major bleeding in patients with atrial fibrillation has been predicted using structured data and clinical notes [39], while patients with heart failure have been identified using clinical notes only [40]. Moreover, medical reports written in the Italian language have been used to identify arrhythmia events [41].

\section{Peripheral and Coronary Arterial Disease}

Several studies used NLP to extract cases of peripheral arterial disease (PAD) and critical limb ischemia from clinical notes $[42,43]$, including a genome-wide associated study, focusing on PAD to identify drugs, diseases, signs/symptoms, anatomical sites, and procedures [44]. Leeper et al [45] used NLP to identify PAD patients to conduct a safety surveillance study on exposure to Cilostazol, finding complications of malignant arrhythmia and sudden death not observed in association with the drug. Furthermore, Clinical Text Analysis Knowledge Extraction System (cTAKES) has been used to process clinical history of diabetic patients to predict development of PAD [46].

\section{Hypertension}

Work on hypertension has been principally focused on NLP to extract relevant indicators, comorbidities, and drug therapies [21]. Analysis of clinical narratives in the Bulgarian language of 100 million outpatient notes was used to extract numerical blood pressure values with a high sensitivity and recall [47], while term hypertension was extracted from free-text notes, using a rule-based, open-source tool [48]. Clinical notes and several types of medical documents were also used to identify hypertensive individuals using open-source medication information extraction (IE) system MedEx [49].

\section{Right-Sided, Left-Sided, and Congestive Heart Failure}

Byrd et al [50] and Jonnagaddala et al [20] proposed a hybrid NLP model to identify Framingham heart failure signs and symptoms from clinical notes and EHRs (ie, classifying whether Framingham criteria are asserted). Left ventricular ejection fraction was extracted from free-text echocardiogram reports [51], while unstructured, longitudinal EHRs of diabetic patients were used to extract relevant information of heart disease, using naïve Bayes and conditional random field (CRF) classifiers [52].

Wang et al [53] proposed a system for the identification of congestive heart failure (CHF) from EHRs, which they prospectively validated. Furthermore, left ventricular ejection fraction plus the associated qualitative and quantitative values were used to identify patients at risk of CHF [54], while free-text notes were used to distinguish left and right heart failure [55].

\section{Heart Failure Identification}

Topaz et al [56] developed an algorithm to identify heart failure (HF) patients with ineffective self-management of diet, physical activity, adherence to medication, and clinical appointments using discharge summary notes, while Garvin et al [57] focused on the quality of care for HF patients. Vijayakrishnan et al [58] explored the application of a previously validated text and data-mining tool to identify the presence of HF signs and symptoms criteria in the EHRs of a large primary care population. They found that HF signs and symptoms were documented much more frequently among the eventual HF cases, years before the first diagnosis as well, thus suggesting a potential future role for early detection of HF. Last, regular expressions were used to identify predefined psychosocial factors that served as predictors of the likelihood to be readmitted to the hospital after a case of HF [59].

\section{Neoplasms}

\section{Overview}

This section reviews a number of cancer-related studies, including detection of multiple types of cancer $[60,61]$, 
extracting tumor characteristics and tumor-related information [62-64], disease trajectories of patients with cancer [65], cancer recurrence $[23,66]$, and detection of stage of cancer $[67,68]$.

Kasthurirathne et al [60] evaluated the performance of common classification algorithms to detect cancer cases from free-text pathology reports using nondictionary approaches. Yim et al [62] explored a machine learning algorithm to extract tumor characteristics by applying reference resolution on radiology reports. Jensen et al [65] developed a methodology that allows disease trajectories of cancer patients to be estimated from the clinical text. Napolitano et al [67] facilitated the extraction of information relevant to cancer staging, proposing a model for semistructured reports that outperformed the model for unstructured reports alone.

A number of studies have focused on different applications of NLP in pathology, histopathology, and radiology reports [69], including extracting relevant domain entities from narrative cancer pathology reports [70], negation detection of medical entities in pathology reports [71], sentence translation from pathology reports into graph representations [72], extracting information from pathology reports and pathology classifications $[73,74]$, and named entity recognition from histopathology notes [75].

The three most common types of cancers found are breast cancer $(n=8)$, colorectal cancer $(n=7)$, and prostate cancer $(n=4)$.

\section{Breast Cancer}

Carrell et al [66] proposed an NLP system to process clinical text to identify breast cancer recurrences, while Castro et al [22] addressed the automated Breast Imaging-Reporting and Data System (BI-RADS) categories extraction from breast radiology reports. Miller et al [76] proposed a tool for coreference resolution in clinical texts evaluated within the domain (colon cancer) and between domains (breast cancer). Mykowiecka et al [77] propose a rule-based IE system evaluated on mammography reports. Bozkurt et al [78] developed NLP methods to recognize lesions in free-text mammography reports and extract their corresponding relationships, producing a complete information frame for each lesion.

\section{Colorectal and Prostate Cancer}

EHRs and NLP were used to identify patients in need of colorectal cancer screening [79] and detect colonoscopy-related concepts as well as temporal-related information [80]. Additionally, EHRs and NLP were used to also identify patients with prostate biopsies positive for prostatic adenocarcinoma [81].

\section{Liver and Pancreatic Cancer}

Ping et al [82] extracted textual information concerning a set of predefined clinical concepts from a variety of clinical reports for patients with liver cancer, while Al-Haddad et al [83] identified patients with confirmed surgical pathology diagnoses of intraductal papillary mucinous neoplasms.

\section{Endocrine, Nutritional, and Metabolic Diseases}

Applications of NLP in the domain of endocrine, nutritional, and metabolic diseases include negation detection and mention of family history in free-text notes [84] and assigning temporal tags to medical concepts [85]; obesity $[25,86]$ and diabetes identification [77,87-89]; and diabetes complications such as foot examination findings [90], vision loss [91], and quantifying the occurrence of hypoglycemia [24].

Two support vector machines (SVMs) were combined to automatically identify obesity types by extracting obesity and diabetes-related concepts from clinical text [86] in addition to patient identification [92]. An SVM-based system was developed and validated to identify EHR progress notes pertaining to diabetes [87], while foot examination findings from clinical reports [90] were used to predict quality of life [93]. Additionally, an analysis of a large EHR database was used to quantify occurrence of hypoglycemia [24].

\section{Other Disease Categories}

The remaining 16 papers focused on processing clinical notes of different types of chronic diseases. Three studies concern diseases of the musculoskeletal system and connective tissue, in particular classification of snippets of text related to axial spondyloarthritis in the EMRs of US military veterans using NLP and SVM [94], phenotyping systemic lupus erythematosus [95], and identification of rheumatoid arthritis patients via ontology-based NLP and logistic regression [96]. In the domain of diseases of the digestive system, Chen et al [97] used natural language features from pathology reports to identify celiac disease patients, Soguero-Ruiz et al [98] used feature selection and SVMs to detect early complications after colorectal cancer, and Chang et al [99] integrated rule-based NLP on notes with ICD-9s and lab values in an algorithm to better define and risk-stratify patients with cirrhosis.

Two papers evaluated deep learning in a multidisease domain. In particular, Miotto et al [3] derived a general purpose patient representation from aggregated EHRs (structured clinical data and clinical notes) based on neural networks that facilitates clinical predictive modeling given the patient status. Clinical notes were parsed using the National Center for Biomedical Ontology's Open Biomedical Annotator to extract medical terms and further processed using topic modeling (latent Dirichlet allocation). Shi et al [100] proposed assessing disease risk from patient clinical notes using word embeddings and convolutional neural networks with full connection layer.

Neural networks were also used to process clinical notes for phenotyping psychiatric diagnosis [101]. In particular, this model included two neural networks, one highly accurate at rejecting patients but poor at identifying suitable ones and the other one with the opposite capabilities. In the same domain of mental and behavioral disorders, comorbidity networks were derived from the patient notes at the largest Danish psychiatric hospital in order to extract disease correlations [102].

IE from clinical notes based on NLP was also used to (1) screen computed tomography reports for invasive pulmonary mold [103], (2) discover the co-occurrences of chronic obstructive pulmonary disease with other medical terms [104], (3) quantify the relationship between aggregated preoperative risk factors and cataract surgery complications [105], (4) detect patients with multiple sclerosis from the clinical notes prior to the initial 
recognition by their health care providers [106], and (5) identify patients on dialysis in the Multiparameter Intelligent Monitoring in Intensive Care II (MIMIC-II) publicly available dataset [107].

Last, Pivovarov and Elhadad [108] used clinical notes of patients with chronic kidney disease to validate a novel model to compute the similarity of two medical concepts by combining complementary information derived from usage patterns of clinical documentation, accepted definitions, and position of the concepts in an ontology.

\section{Information Extraction Methods}

In order to understand trends in NLP methods for chronic diseases, in this review we have analyzed papers with respect to the methods employed (machine vs rule-based learning). While there is an increasing use of machine learning methods in comparison to rule-based (as shown in Figure 3), it is not as pronounced as we had expected considering the superior performance of machine learning algorithms shown in the NLP literature [109]. This result may reflect the fact that we are still currently witnessing a transition from rule-based methods to machine learning algorithms, with rule-based methods used as a baseline to compare the performance of machine learning approaches.

Our review identified 16 papers that employed hybrid approaches combining rule-based and machine learning methods. Out of these, 2 papers describe work to identify diseases, risk factors, medications, and time attributes. In particular, a hybrid pipeline based on CRFs, SVMs, and rule-based approaches was used to identify negation information and normalize temporal expressions [29], while a series of SVM models in conjunction with manually built lexicons were used to classify triggers specific to each risk factor [33].

We identified 24 papers that focused on comparison between performance of rule-based and machine learning methods. Typically, the rule-based methods were used as a baseline to test the performance against machine learning algorithms.

As for rule-based approaches, the methods in this review include dictionary lookup [110-112], terminology identification based on domain ontologies $[3,42,45,58]$, various types of manually defined rules [37,113], and regular expressions patterns [114,115].

The most widely used machine learning approach is SVMs, having been used for predicting heart disease in medical records $[32,46]$, identifying EHR progress notes pertaining to diabetes [94], and categorizing breast radiology reports according to BI-RADS [22].

Naïve Bayes was the second most frequent approach, being used to predict heart disease in medical records $[30,80]$, classify smoking status [52], search EMR records to identify multiple sclerosis [106], and classify EMR records for obesity [86] and cancer $[60,65,67]$. CRFs are the third most frequent approach, have been used to predict heart disease in medical records [29,32], identify EHR progress notes pertaining to diabetes [85], categorize breast radiology reports [22], and identify tumor attributes in radiology reports [63]. Lastly, random forests were used for predicting heart disease [53], classifying cancer types [60], and identifying hypertension [49].

Figure 3. Natural language processing rule-based methods versus machine learning for chronic diseases.

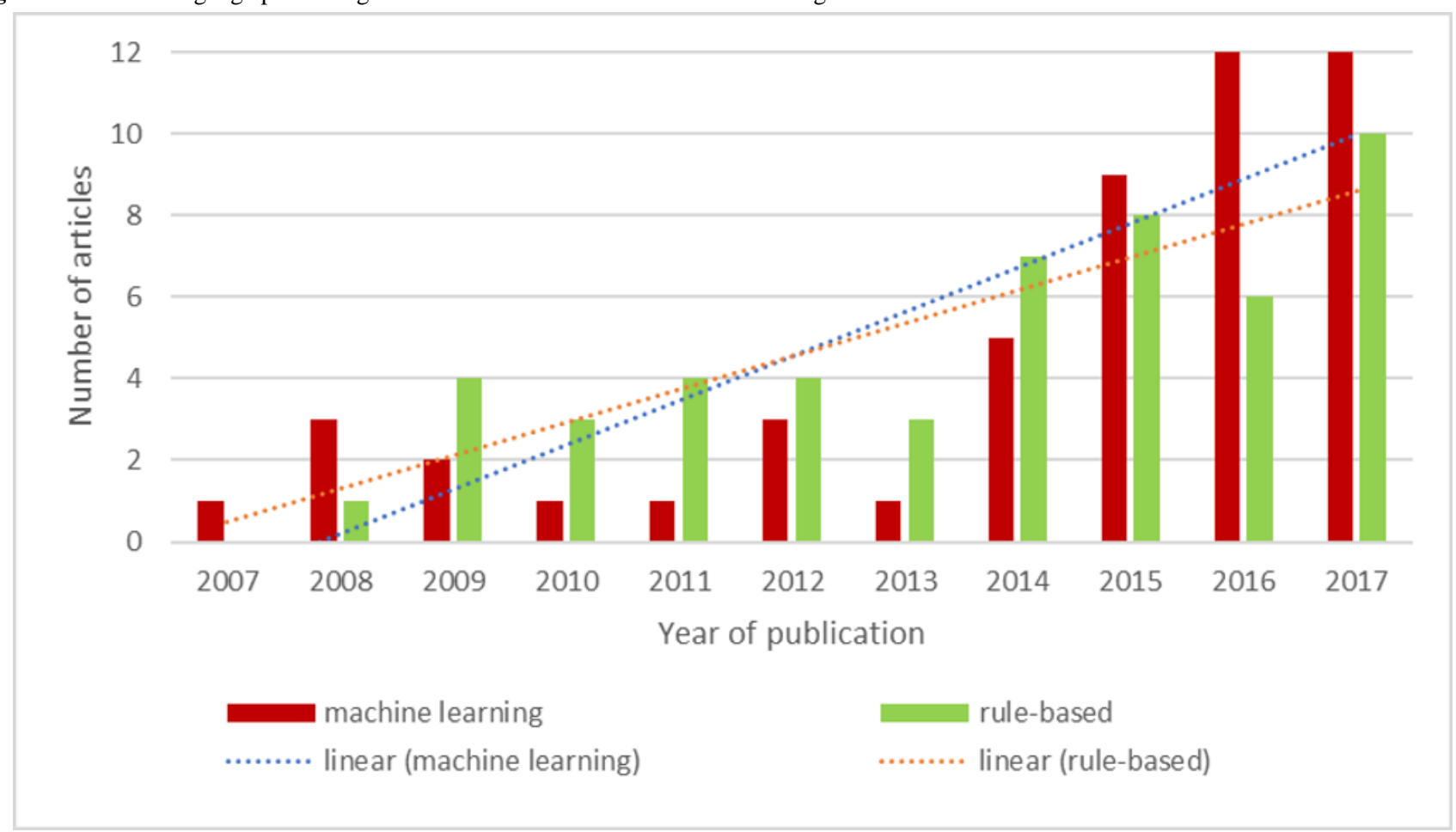


Table 2. Most frequently used natural language processing methods and the corresponding number of papers.

\begin{tabular}{ll}
\hline Method & Papers (n) \\
\hline Support vector machine & 18 \\
Naïve Bayes & 11 \\
Conditional random fields & 7 \\
Random forest & 4 \\
Maximum entropy & 3 \\
Decision tree & 3 \\
Deep neural networks & 3 \\
Logistic regression & 3 \\
Rule-based methods & 74 \\
\hline
\end{tabular}

It is interesting to note that there are only 3 papers using approaches based on deep learning [3,100,101], as shown in Table 2. In particular, Geraci et al [101] apply deep neural networks to EMRs to identify suitable candidates for a study on youth depression. Miotto et al [3] present a method to derive a patient representation that facilitates clinical predictive modeling from aggregate EHRs, including clinical narratives. They represented free-text notes using topic modeling. This method significantly outperformed those achieved by standard feature learning strategies. Finally, Shi et al [100] propose a disease assessment model based on clinical notes, using convolutional neural network for disease risk assessment. The experiment involved patients with cerebral infarction, pulmonary infection, and coronary atherosclerotic heart disease.

\section{Natural Language Processing Tasks, Methods, and Datasets}

The NLP works described in the reviewed papers and associated approaches reveal that the most frequently described tasks are text classification and entity recognition. The majority of the papers describe text classification tasks using standard approaches in NLP such as SVM $(n=12)$ and naïve Bayes $(n=4)$. Entity recognition approaches are based on manually developed resources (dictionary, regular expressions, handwritten rules) as well as methods based on machine learning. As for the former, there are dictionary-based approaches $(n=5)$ and those relying on regular expressions $(n=12)$. As for the latter, the approaches are mainly based on standard machine language techniques such as CRF and deep learning. A few papers describe approaches to coreference resolution $(n=2)$ and negation detection $(n=3)$. Coreference resolution is addressed using SVM, while negation detection is based on SVM $(n=2)$ or manual rules $(n=1)$.

Regarding datasets, the majority of the papers describe experiments run on datasets that are not publicly available (typically clinical data collected at research-based health care institutions and exploited by in-house NLP teams). On the other hand, out of 16 papers involving publicly available corpora, 12 exploit the Informatics for Integrating Biology and the Bedside (i2b2) datasets. The other 4 public datasets used are MIMIC-II [107], PhenoCHF [116], Temporal Histories of Your Medical Event (THYME), and Cancer Deep Phenotype Extraction (DeepPhe) [76].

\section{Comparisons to Other Systematic Reviews}

Interest in using NLP for the automated processing of medical records, and in particular of free-text clinical notes, is increasing, exemplified by a number of recent reviews of the field. Yet none of these works focuses solely on chronic diseases, where the amount of patient clinical notes tends to be larger than other domains or provides specific recommendations on how to advance the field toward a clinical adoption that helps in treating people with chronic conditions. Here we briefly provide a summary of previous works partially related to the work presented in this paper.

Ford et al [13] present a systematic review of 67 papers using IE techniques applied to medical records for the purpose of case detection (ie, finding occurrences of specific medical conditions). Similarly, Kreimeyer et al [117] review 86 papers focusing on clinical NLP systems and a set of 71 associated NLP tasks.

The work by Shivade et al [14] reviews 97 papers aiming at identifying patient cohorts for further medical studies. Different from our work, theirs is not limited to investigation of studies using NLP and text mining but includes rule-based approaches, which do not make use of the textual part of the medical records. They observe, however, that the use of machine learning and statistical and NLP methods is on the rise compared to rule-based systems.

Abbe et al [118] consider applications of text mining in psychiatry through a PRISMA-based review. The study evaluates the application of specific NLP techniques in relation to the goal of the studies, first qualitatively, and then with a cluster analysis of the topics of selected abstracts. It identifies four main themes in the publications taken into consideration: (1) psychopathology (2), patient perspective, (3) medical records, and (4) medical literature. The scope of this review only partially overlaps with our own, given the narrow thematic analysis and inclusion of studies that deal with IE from other textual resources, such as patient perspectives.

The review by Spasic et al [119] focuses on cancer research. The authors classify the studies by cancer type and type of processed document. They do not focus solely on studies based on medical records or other types of clinical documents but also include meta-studies that apply text mining techniques to 
PubMed publications. They classify NLP applications in four categories: named entity recognition, IE, text classification, and information retrieval. Their investigation reveals a predominance of symbolic approaches (dictionary and rule-based).

The work by Pons et al [120] is a systematic review of NLP applications in the area of radiology. After initial preselection based on abstracts, a detailed review of the full text of the selected papers ultimately yields 67 publications, all deemed to consider practical applications of NLP in radiology. The selected publications are then grouped into five broad categories depending on the specific application: diagnostic surveillance, cohort building, query-case retrieval, quality assessment of radiological practice, and clinical support services. The authors provide a detailed comparative analysis of the performance reported in each publication, grouping them by application category.

Closest to our work is a systematic review by Wang et al [18] that has focused on IE applications; however, our review additionally includes methodologies used in analysis of clinical notes, providing a wider set of articles. We believe that our review has a broader and more recent coverage of chronic diseases, followed by detailed analysis for each disease, compared with previous reviews, which have focused on specific conditions such as cancer [119], psychiatry [118], radiology [120], or IE applications [18].

\section{Publication Venues}

The 106 articles considered in this review were published in 50 unique venues. Figure 4 illustrates how we manually sorted publication venues into three categories: (1) clinical medicine, (2) medical informatics, and (3) computer science. We observed that most of the studies were published in medical informatics journals. Figure 5 shows an increasing trend in number of publications over the years (except for the year 2018 due to partial-year retrieval) implying an increasing interest in the application of NLP in both clinical and informatics research for chronic diseases.

Figure 4. Categorization of the publication venues.

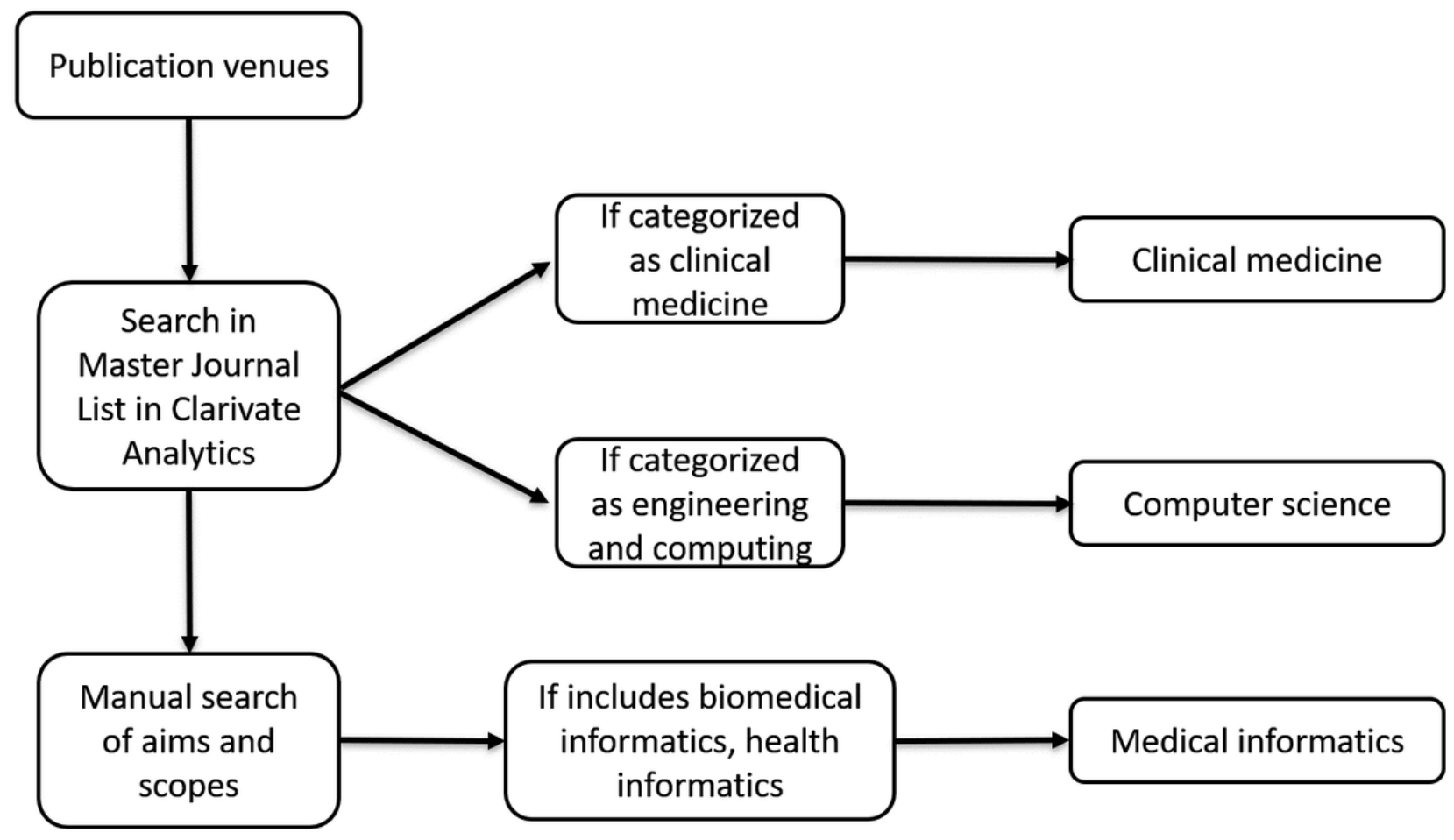


Figure 5. Distribution of included studies according to publication venues.

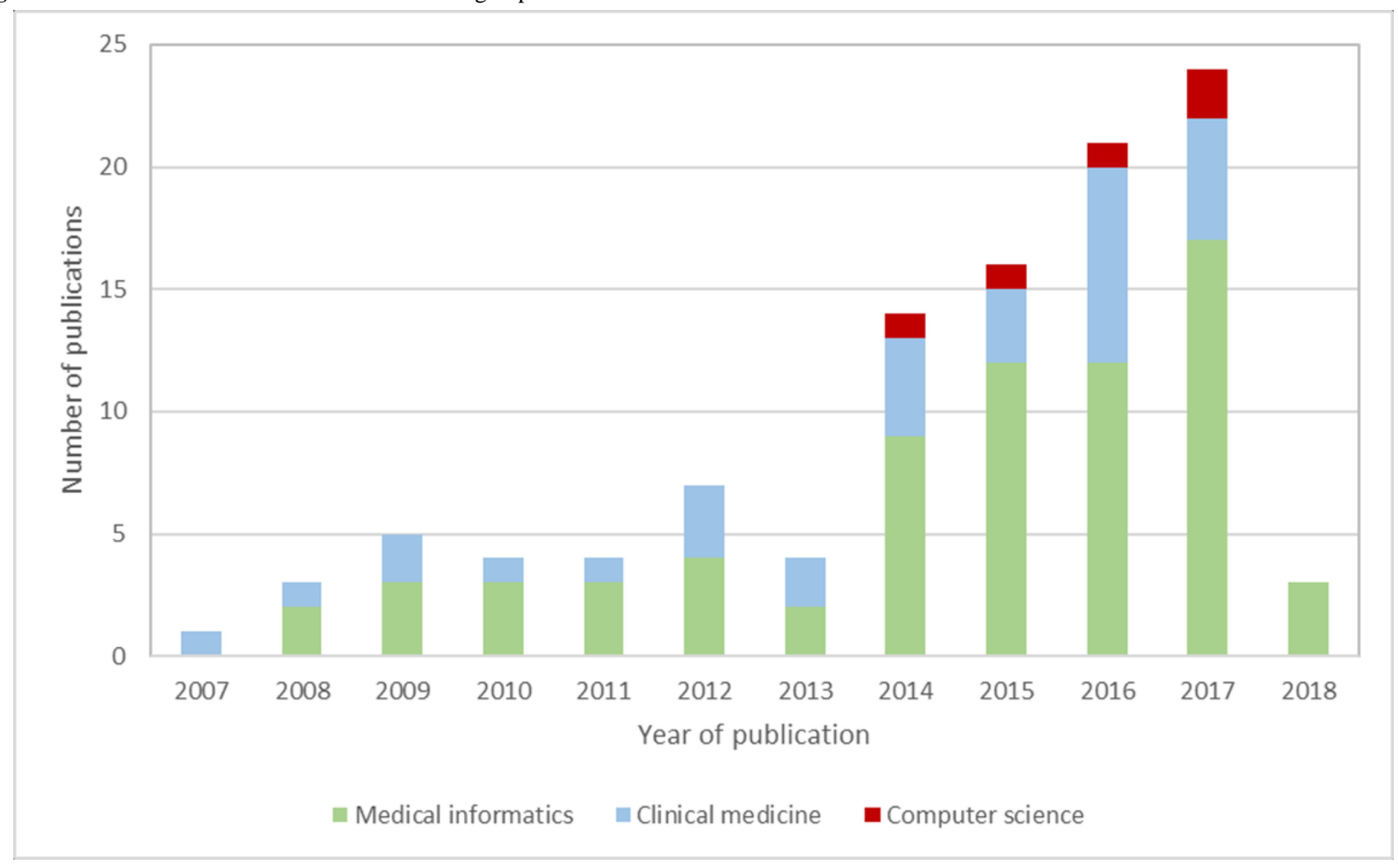

\section{Discussion}

\section{Principal Findings}

Our systematic review has shown that NLP has a wide range of applications for processing clinical notes of diverse chronic diseases (43 unique chronic diseases identified in the analysis). In this respect, there is a significant increase in the use of machine learning compared with rule-based methods. Despite the potential offered by deep learning, the majority of papers still rely on shallow classifiers. In fact, only a handful of studies (ie, 3 papers) made use of deep classifiers or general deep learning methods for NLP. This was unexpected, considering the potential of deep learning for text processing [121]. Our hypothesis is that since deep learning is still an emerging area, initial applications in the clinical domain may have been published in workshops, conference proceedings, and the e-print repository arXiv rather than journals, the focus of this review. In this respect, a keyword search in arXiv for "deep learning," and "clinical notes," "medical notes," or "clinical narratives" for the previous five years (2013-2018) shows a significant growth of papers: 7 from 2013 to 2015, 13 in 2016, 19 in 2017, and 22 in 2018. In addition, the longer review time for journals has likely contributed to this outcome for the more recent papers. We expect this result to shift in the coming years as an increasing amount of work based on deep learning to process clinical notes is published in peer-reviewed journals.

Another finding from our review is that the majority of papers reviewed identify risk factors for a particular disease and classify a clinical note by a certain disease phenotype. However, there are only a handful of papers that extract comorbidities from the free-text or integrate clinical notes with structured data for prediction and longitudinal modeling of trajectories of patients with chronic diseases. Such an outcome could be related to the use of data analysis methods and algorithms (such as shallow classifiers and rule-based approaches highlighted earlier) that do not have the capability to capture temporal and longitudinal relationships between clinical variables and in turn capture disease evolution. Tools (such as MetaMap) and methods (such as mapping n-grams to ontologies) used may have been other influencing factors. While these tools allow extracting meaningful medical information from the text, inherently they reduce the possibility to derive more complex relationships, principally due to phrase structure (for example "breast and lung cancer" may be identified only as "breast" and "lung cancer" rather than both "breast cancer" and "lung cancer"). However, the use of relatively simple methods is advantageous in terms of interpretability of predictions-a highly important aspect in clinical domain-whereas it still represents a significant issue for more complex methods.

Our review has retrieved only a few studies on the topic of extracting word embeddings from clinical notes. This may be due to insufficient available data to train the algorithms as well as the fact that embedding methods have been developed only recently. The issue of insufficient training data could be addressed using transfer learning methods, while using precomputed embeddings for specific diseases or categories of diseases could be useful to effectively capture longitudinal relationships.

Our review has shown that SVM and naïve Bayes algorithms were most often used for machine learning-based tasks or in combination with rule-based methods. This may be due to the popularity of these algorithms as well as because naïve Bayes, being a relatively simple algorithm, requires relatively small 
amount of training data (in comparison with deep classifiers, for example). Although it is not feasible to directly compare algorithmic performance of the studies that we considered (due to both diversity of data and challenges addressed), we have noted that the most commonly reported performance measures were sensitivity (recall), positive predictive value (precision), and $F$ score.

Finally, our review has reinforced the fact that availability of public datasets remains scarce. This outcome was largely expected given the sensitivity of clinical data in addition to all the legal and regulatory issues, including the Health Insurance Portability and Accountability Act and the Data Protection Directive (Directive 95/46/EC) of the European Law (superseded by the General Data Protection Regulation 2016/679). As a result, the studies reviewed in this paper typically came from research-based health care institutions with in-house NLP teams having access to clinical data. Therefore, the need remains for shared tasks such as i $2 \mathrm{~b} 2$ and access to data that would increase participation in clinical NLP and contribute to improvements of NLP methods and algorithms targeting clinical applications.

\section{Limitations}

This review has examined the last 11 years of clinical IE applications literature and may have the following limitations. The review is limited to journal articles written in the English language, and papers written in other languages, especially papers that consider clinical narratives, may provide additional results. In addition, papers using clinical articles from non-EHR systems have not been considered. Finally, focusing on the clinical domain may have introduced a bias with respect to the methods reviewed (rule-based vs machine learning), as rule-based methods are more prevalent in the clinical domain compared with other domains [122].

\section{Recommendations}

Our review has shown that there is a clear necessity for clinical NLP methods to evolve beyond extraction of clinical concepts and focus more on concept understanding (ie, not only understanding of relationships between concepts but incorporation of clinical facts, domain knowledge, and general knowledge in the reasoning process). In this review, we have not encountered work that attempts to bridge the gap between concept extraction and concept understanding.

We have devised the following specific recommendations:

1. Focus on recognition of relationships among clinical concepts and entities. While progress has been made in recognizing entities in textual narratives (such as diseases, drugs, procedures), further efforts must be focused on automatic inference of relationships between these entities (for example, drug A causes adverse event B for chronic disease $\mathrm{C}$ ), which in turn would allow deeper understanding of clinical text.

2. Temporal extraction, automated mark-up and normalization of temporal information from natural language texts, is an important aspect. This is especially relevant for clinical text as disease progression and clinical events are typically recorded chronologically, with specific events being significant only in a particular temporal context. As such, significant attention should be given to temporal extraction considering its implication in clinical context, especially since none of the works in this review dealt with temporal extraction (or used crude methods such as timestamps of clinical notes).

3. Scarcity of annotated clinical corpora has raised the need to exploit alternative sources of domain knowledge. In addition to mainstream sources such as biomedical literature, encyclopedias, and textbooks, automatic diagnostic and decision support systems could be exploitable (such as DXplain [123]). Transfer learning, a method of transferring knowledge from existing corpora in other domains to the clinical domain, also holds great potential and should be investigated in more detail.

4. Significant advances in effective clinical NLP will depend on large-scale corpora becoming available to researchers. While shared tasks such as i2b2 and its successor $n 2 c 2$ are steps in the right direction, further incentives will be required such as developing mechanisms that would empower patients to donate their anonymized data or even providing algorithms that run on clinical text inside care institutions.

\section{Acknowledgments}

This work was partially supported by the European Union's Horizon 2020 research and innovation program under grant agreement \#769765.

\section{Conflicts of Interest}

None declared.

\section{Multimedia Appendix 1}

Search strategy.

\section{[PDF File (Adobe PDF File), 178KB-Multimedia Appendix 1]}

\section{Multimedia Appendix 2}

Complete list of reviewed papers, chronic diseases and their classifications, algorithms used, publication venues, and excluded papers. 
[XLSX File (Microsoft Excel File), 107KB-Multimedia Appendix 2]

\section{References}

1. World Health Organization. WHO Global status report on noncommunicable diseases 2014 URL: https://www.who.int/

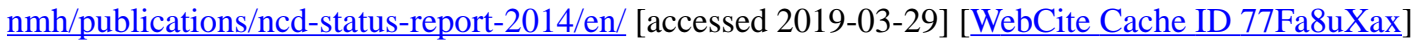

2. Kruse CS, Kothman K, Anerobi K, Abanaka L. Adoption factors of the electronic health record: a systematic review. JMIR Med Inform 2016 Jun 01;4(2):e19. [doi: 10.2196/medinform.5525] [Medline: 27251559]

3. Miotto R, Li L, Kidd BA, Dudley JT. Deep patient: an unsupervised representation to predict the future of patients from the electronic health records. Sci Rep 2016 Dec 17;6:26094 [FREE Full text] [doi: 10.1038/srep26094] [Medline: 27185194]

4. Jensen P, Jensen L, Brunak S. Mining electronic health records: towards better research applications and clinical care. Nat Rev Genet 2012 May 02;13(6):395-405. [doi: 10.1038/nrg3208] [Medline: 22549152]

5. Goldstein BA, Navar AM, Pencina MJ, Ioannidis JPA. Opportunities and challenges in developing risk prediction models with electronic health records data: a systematic review. J Am Med Inform Assoc 2017 Jan;24(1):198-208. [doi: 10.1093/jamia/ocw042] [Medline: 27189013]

6. Ye C, Fu T, Hao S, Zhang Y, Wang O, Jin B, et al. Prediction of incident hypertension within the next year: prospective study using statewide electronic health records and machine learning. J Med Internet Res 2018 Jan 30;20(1):e22 [FREE Full text] [doi: 10.2196/jmir.9268] [Medline: 29382633]

7. Miotto R, Wang F, Wang S, Jiang X, Dudley JT. Deep learning for healthcare: review, opportunities and challenges. Brief Bioinform 2017 May 06. [doi: 10.1093/bib/bbx044] [Medline: 28481991]

8. Jensen K, Soguero-Ruiz C, Oyvind MK, Lindsetmo R, Kouskoumvekaki I, Girolami M, et al. Analysis of free text in electronic health records for identification of cancer patient trajectories. Sci Rep 2017 Dec 07;7:46226 [FREE Full text] [doi: 10.1038/srep46226] [Medline: 28387314]

9. Flynn R, Macdonald TM, Schembri N, Murray GD, Doney ASF. Automated data capture from free-text radiology reports to enhance accuracy of hospital inpatient stroke codes. Pharmacoepidemiol Drug Saf 2010 Aug;19(8):843-847. [doi: 10.1002/pds.1981] [Medline: 20602346]

10. Popejoy LL, Khalilia MA, Popescu M, Galambos C, Lyons V, Rantz M, et al. Quantifying care coordination using natural language processing and domain-specific ontology. J Am Med Inform Assoc 2015 Apr;22(e1):e93-e103 [FREE Full text] [doi: 10.1136/amiajnl-2014-002702] [Medline: 25324557]

11. Yang H, Spasic I, Keane JA, Nenadic G. A text mining approach to the prediction of disease status from clinical discharge summaries. J Am Med Inform Assoc 2009;16(4):596-600 [FREE Full text] [doi: 10.1197/jamia.M3096] [Medline: 19390098]

12. Wei W, Teixeira PL, Mo H, Cronin RM, Warner JL, Denny JC. Combining billing codes, clinical notes, and medications from electronic health records provides superior phenotyping performance. J Am Med Inform Assoc 2016 Apr;23(e1):e20-e27 [FREE Full text] [doi: 10.1093/jamia/ocv130] [Medline: 26338219]

13. Ford E, Carroll JA, Smith HE, Scott D, Cassell JA. Extracting information from the text of electronic medical records to improve case detection: a systematic review. J Am Med Inform Assoc 2016 Dec;23(5):1007-1015 [FREE Full text] [doi: 10.1093/jamia/ocv180] [Medline: 26911811]

14. Shivade C, Raghavan P, Fosler-Lussier E, Embi PJ, Elhadad N, Johnson SB, et al. A review of approaches to identifying patient phenotype cohorts using electronic health records. J Am Med Inform Assoc 2014;21(2):221-230 [FREE Full text] [doi: 10.1136/amiajnl-2013-001935] [Medline: 24201027]

15. Abbe A, Grouin C, Zweigenbaum P, Falissard B. Text mining applications in psychiatry: a systematic literature review. Int J Methods Psychiatr Res 2016 Dec;25(2):86-100. [doi: 10.1002/mpr.1481] [Medline: 26184780]

16. Spasić I, Livsey J, Keane JA, Nenadić G. Text mining of cancer-related information: review of current status and future directions. Int J Med Inform 2014 Sep;83(9):605-623 [FREE Full text] [doi: 10.1016/j.ijmedinf.2014.06.009] [Medline: 25008281]

17. Pons E, Braun LMM, Hunink MGM, Kors JA. Natural language processing in radiology: a systematic review. Radiology 2016 May;279(2):329-343. [doi: 10.1148/radiol.16142770] [Medline: 27089187]

18. Wang Y, Wang ZF, Rastegar-Mojarad M, Moon S, Shen F, Afzal N, et al. Clinical information extraction applications: a literature review. J Biomed Inform 2018 Dec;77:34-49 [FREE Full text] [doi: 10.1016/j.jbi.2017.11.011] [Medline: 29162496]

19. Moher D, Liberati A, Tetzlaff J, Altman DG. Preferred reporting items for systematic reviews and meta-analyses: the PRISMA statement. PLoS Med 2009 Jul 21;6(7):e1000097 [FREE Full text] [doi: 10.1371/journal.pmed.1000097] [Medline: 19621072]

20. Jonnagaddala J, Liaw S, Ray P, Kumar M, Chang N, Dai H. Coronary artery disease risk assessment from unstructured electronic health records using text mining. J Biomed Inform 2015 Dec;58 Suppl:S203-S210 [FREE Full text] [doi: 10.1016/j.jbi.2015.08.003] [Medline: 26319542]

21. Backenroth D, Chase HS, Wei Y, Friedman C. Monitoring prescribing patterns using regression and electronic health records. BMC Med Inform Decis Mak 2017 Dec 19;17(1):175 [FREE Full text] [doi: 10.1186/s12911-017-0575-5] [Medline: $\underline{29258594]}$ 
22. Castro SM, Tseytlin E, Medvedeva O, Mitchell K, Visweswaran S, Bekhuis T, et al. Automated annotation and classification of BI-RADS assessment from radiology reports. J Biomed Inform 2017 Dec;69:177-187 [FREE Full text] [doi: 10.1016/j.jbi.2017.04.011] [Medline: 28428140$]$

23. Heintzelman NH, Taylor RJ, Simonsen L, Lustig R, Anderko D, Haythornthwaite JA, et al. Longitudinal analysis of pain in patients with metastatic prostate cancer using natural language processing of medical record text. J Am Med Inform Assoc 2013 Sep;20(5):898-905 [FREE Full text] [doi: 10.1136/amiajnl-2012-001076] [Medline: 23144336]

24. Nunes AP, Yang J, Radican L, Engel SS, Kurtyka K, Tunceli K, et al. Assessing occurrence of hypoglycemia and its severity from electronic health records of patients with type 2 diabetes mellitus. Diabetes Res Clin Pract 2016 Nov;121:192-203. [doi: 10.1016/j.diabres.2016.09.012] [Medline: 27744128]

25. Ware H, Mullett CJ, Jagannathan V. Natural language processing framework to assess clinical conditions. J Am Med Inform Assoc 2009;16(4):585-589 [FREE Full text] [doi: 10.1197/jamia.M3091] [Medline: 19390100]

26. Golden SH, Robinson KA, Saldanha I, Anton B, Ladenson PW. Clinical review: prevalence and incidence of endocrine and metabolic disorders in the United States: a comprehensive review. J Clin Endocrinol Metab 2009 Jun;94(6):1853-1878 [FREE Full text] [doi: 10.1210/jc.2008-2291] [Medline: 19494161]

27. Sanchis-Gomar F, Perez-Quilis C, Leischik R, Lucia A. Epidemiology of coronary heart disease and acute coronary syndrome. Ann Transl Med 2016 Jul;4(13):256 [FREE Full text] [doi: 10.21037/atm.2016.06.33] [Medline: 27500157]

28. Liao KP, Ananthakrishnan AN, Kumar V, Xia Z, Cagan A, Gainer VS, et al. Methods to develop an electronic medical record phenotype algorithm to compare the risk of coronary artery disease across 3 chronic disease cohorts. PLoS One 2015;10(8):e0136651 [FREE Full text] [doi: 10.1371/journal.pone.0136651] [Medline: 26301417]

29. Chen Q, Li H, Tang B, Wang X, Liu X, Liu Z, et al. An automatic system to identify heart disease risk factors in clinical texts over time. J Biomed Inform 2015 Dec;58 Suppl:S158-S163 [FREE Full text] [doi: 10.1016/j.jbi.2015.09.002] [Medline: 26362344]

30. Torii M, Fan J, Yang W, Lee T, Wiley MT, Zisook DS, et al. Risk factor detection for heart disease by applying text analytics in electronic medical records. J Biomed Inform 2015 Dec;58 Suppl:S164-S170 [FREE Full text] [doi: 10.1016/j.jbi.2015.08.011] [Medline: 26279500]

31. Karystianis G, Dehghan A, Kovacevic A, Keane JA, Nenadic G. Using local lexicalized rules to identify heart disease risk factors in clinical notes. J Biomed Inform 2015 Dec;58 Suppl:S183-S188 [FREE Full text] [doi: 10.1016/j.jbi.2015.06.013] [Medline: 26133479]

32. Yang H, Garibaldi JM. A hybrid model for automatic identification of risk factors for heart disease. J Biomed Inform 2015 Dec;58 Suppl:S171-S182 [FREE Full text] [doi: 10.1016/j.jbi.2015.09.006] [Medline: 26375492]

33. Roberts K, Shooshan SE, Rodriguez L, Abhyankar S, Kilicoglu H, Demner-Fushman D. The role of fine-grained annotations in supervised recognition of risk factors for heart disease from EHRs. J Biomed Inform 2015 Dec;58 Suppl:S111-S119 [FREE Full text] [doi: 10.1016/j.jbi.2015.06.010] [Medline: 26122527]

34. Pakhomov S, Shah N, Hanson P, Balasubramaniam S, Smith S. Automated processing of electronic medical records is a reliable method of determining aspirin use in populations at risk for cardiovascular events. Inform Prim Care 2010;18(2):125-133 [FREE Full text] [Medline: 21078235]

35. Zheng C, Rashid N, Koblick R, An J. Medication extraction from electronic clinical notes in an integrated health system: a study on aspirin use in patients with nonvalvular atrial fibrillation. Clin Ther 2015 Sep;37(9):2048-2052. [doi: 10.1016/j.clinthera.2015.07.002] [Medline: 26233471]

36. Patterson OV, Freiberg MS, Skanderson M, Brandt CA, DuVall SL. Unlocking echocardiogram measurements for heart disease research through natural language processing. BMC Cardiovasc Disord 2017 Dec 12;17(1):151 [FREE Full text] [doi: 10.1186/s12872-017-0580-8] [Medline: 28606104]

37. Tian Z, Sun S, Eguale T, Rochefort CM. Automated extraction of VTE events from narrative radiology reports in electronic health records: a validation study. Med Care 2017 Dec;55(10):e73-e80 [FREE Full text] [doi:

10.1097/MLR.0000000000000346] [Medline: 25924079]

38. Ross EG, Shah N, Leeper N. Statin intensity or achieved LDL? Practice-based evidence for the evaluation of new cholesterol treatment guidelines. PLoS One 2016;11(5):e0154952 [FREE Full text] [doi: 10.1371/journal.pone.0154952] [Medline: 27227451]

39. Wang SV, Rogers JR, Jin Y, Bates DW, Fischer MA. Use of electronic healthcare records to identify complex patients with atrial fibrillation for targeted intervention. J Am Med Inform Assoc 2017 Mar 01;24(2):339-344. [doi: 10.1093/jamia/ocw082] [Medline: 27375290]

40. Pakhomov S, Weston S, Jacobsen S, Chute C, Meverden R, Roger V. Electronic medical records for clinical research: application to the identification of heart failure. Am J Manag Care 2007 Jun;13(6 Part 1):281-288 [FREE Full text] [Medline: $\underline{17567225]}$

41. Viani N, Larizza C, Tibollo V, Napolitano C, Priori SG, Bellazzi R, et al. Information extraction from Italian medical reports: an ontology-driven approach. Int J Med Inform 2018 Mar;111:140-148. [doi: 10.1016/j.ijmedinf.2017.12.013] [Medline: 29425625] 
42. Afzal N, Mallipeddi VP, Sohn S, Liu H, Chaudhry R, Scott CG, et al. Natural language processing of clinical notes for identification of critical limb ischemia. Int J Med Inform 2018 Mar;111:83-89 [FREE Full text] [doi: 10.1016/j.ijmedinf.2017.12.024] [Medline: 29425639]

43. Afzal N, Sohn S, Abram S, Scott CG, Chaudhry R, Liu H, et al. Mining peripheral arterial disease cases from narrative clinical notes using natural language processing. J Vasc Surg 2017 Dec;65(6):1753-1761 [FREE Full text] [doi: 10.1016/j.jvs.2016.11.031] [Medline: 28189359]

44. Kullo IJ, Fan J, Pathak J, Savova GK, Ali Z, Chute CG. Leveraging informatics for genetic studies: use of the electronic medical record to enable a genome-wide association study of peripheral arterial disease. J Am Med Inform Assoc 2010;17(5):568-574 [FREE Full text] [doi: 10.1136/jamia.2010.004366] [Medline: 20819866]

45. Leeper NJ, Bauer-Mehren A, Iyer SV, Lependu P, Olson C, Shah NH. Practice-based evidence: profiling the safety of cilostazol by text-mining of clinical notes. PLoS One 2013;8(5):e63499 [FREE Full text] [doi: 10.1371/journal.pone.0063499] [Medline: 23717437]

46. Buchan K, Filannino M, Uzuner O. Automatic prediction of coronary artery disease from clinical narratives. J Biomed Inform 2017 Dec;72:23-32 [FREE Full text] [doi: 10.1016/j.jbi.2017.06.019] [Medline: 28663072]

47. Boytcheva S, Angelova G, Angelov Z, Tcharaktchiev D. Text mining and big data analytics for retrospective analysis of clinical texts from outpatient care. Cybern Inf Technol 2015;1(4):55-77 [FREE Full text] [doi: 10.1515/cait-2015-0055]

48. Jonnagaddala J, Liaw S, Ray P, Kumar M. HTNSystem: hypertension information extraction system for unstructured clinical notes. Lect Notes Comput Sci 2014:219-227 [FREE Full text] [doi: 10.1007/978-3-319-13987-6 21]

49. Teixeira PL, Wei W, Cronin RM, Mo H, VanHouten JP, Carroll RJ, et al. Evaluating electronic health record data sources and algorithmic approaches to identify hypertensive individuals. J Am Med Inform Assoc 2017 Jan;24(1):162-171 [FREE Full text] [doi: 10.1093/jamia/ocw071] [Medline: 27497800]

50. Byrd RJ, Steinhubl SR, Sun J, Ebadollahi S, Stewart WF. Automatic identification of heart failure diagnostic criteria, using text analysis of clinical notes from electronic health records. Int J Med Inform 2014 Dec;83(12):983-992 [FREE Full text] [doi: 10.1016/j.ijmedinf.2012.12.005] [Medline: 23317809]

51. Garvin JH, DuVall SL, South BR, Bray BE, Bolton D, Heavirland J, et al. Automated extraction of ejection fraction for quality measurement using regular expressions in Unstructured Information Management Architecture (UIMA) for heart failure. J Am Med Inform Assoc 2012;19(5):859-866 [FREE Full text] [doi: 10.1136/amiajnl-2011-000535] [Medline: 22437073]

52. Jonnagaddala J, Liaw S, Ray P, Kumar M, Dai H, Hsu C. Identification and progression of heart disease risk factors in diabetic patients from longitudinal electronic health records. Biomed Res Int 2015;2015:636371 [FREE Full text] [doi: 10.1155/2015/636371] [Medline: 26380290]

53. Wang Y, Luo J, Hao S, Xu H, Shin AY, Jin B, et al. NLP based congestive heart failure case finding: a prospective analysis on statewide electronic medical records. Int J Med Inform 2015 Dec;84(12):1039-1047. [doi: 10.1016/j.ijmedinf.2015.06.007] [Medline: 26254876]

54. Kim Y, Garvin JH, Goldstein MK, Hwang TS, Redd A, Bolton D, et al. Extraction of left ventricular ejection fraction information from various types of clinical reports. J Biomed Inform 2017 Dec;67:42-48 [FREE Full text] [doi: 10.1016/j.jbi.2017.01.017] [Medline: 28163196]

55. American Heart Association. Types of Heart Failure URL: https://www.heart.org/en/health-topics/heart-failure/ what-is-heart-failure/types-of-heart-failure [accessed 2019-03-30] [WebCite Cache ID 77FcIDcn5]

56. Topaz M, Radhakrishnan K, Blackley S, Lei V, Lai K, Zhou L. Studying associations between heart failure self-management and rehospitalizations using natural language processing. West J Nurs Res 2017 Jan;39(1):147-165. [doi: 10.1177/0193945916668493] [Medline: 27628125]

57. Garvin JH, Kim Y, Gobbel GT, Matheny ME, Redd A, Bray BE, et al. Automating quality measures for heart failure using natural language processing: a descriptive study in the Department of Veterans Affairs. JMIR Med Inform 2018 Jan 15;6(1):e5 [FREE Full text] [doi: 10.2196/medinform.9150] [Medline: 29335238]

58. Vijayakrishnan R, Steinhubl SR, Ng K, Sun J, Byrd RJ, Daar Z, et al. Prevalence of heart failure signs and symptoms in a large primary care population identified through the use of text and data mining of the electronic health record. J Card Fail 2014 Jul;20(7):459-464 [FREE Full text] [doi: 10.1016/j.cardfail.2014.03.008] [Medline: 24709663]

59. Watson AJ, O'Rourke J, Jethwani K, Cami A, Stern TA, Kvedar JC, et al. Linking electronic health record-extracted psychosocial data in real-time to risk of readmission for heart failure. Psychosomatics 2011;52(4):319-327 [FREE Full text] [doi: 10.1016/i.psym.2011.02.007] [Medline: 21777714]

60. Kasthurirathne SN, Dixon BE, Gichoya J, Xu H, Xia Y, Mamlin B, et al. Toward better public health reporting using existing off the shelf approaches: the value of medical dictionaries in automated cancer detection using plaintext medical data. J Biomed Inform 2017 Dec;69:160-176 [FREE Full text] [doi: 10.1016/j.jbi.2017.04.008] [Medline: 28410983]

61. Osborne JD, Wyatt M, Westfall AO, Willig J, Bethard S, Gordon G. Efficient identification of nationally mandated reportable cancer cases using natural language processing and machine learning. J Am Med Inform Assoc 2016 Nov;23(6):1077-1084. [doi: 10.1093/jamia/ocw006] [Medline: 27026618] 
62. Yim W, Kwan SW, Yetisgen M. Tumor reference resolution and characteristic extraction in radiology reports for liver cancer stage prediction. J Biomed Inform 2016 Dec;64:179-191 [FREE Full text] [doi: 10.1016/j.jbi.2016.10.005] [Medline: $\underline{27729234]}$

63. Yim W, Kwan SW, Yetisgen M. Classifying tumor event attributes in radiology reports. J Assoc Inform Sci Technol 2017 Sep 14;68(11):2662-2674. [doi: 10.1002/asi.23937]

64. Wang H, Zhang W, Zeng Q, Li Z, Feng K, Liu L. Extracting important information from Chinese Operation Notes with natural language processing methods. J Biomed Inform 2014 Apr;48:130-136 [FREE Full text] [doi: 10.1016/j.jbi.2013.12.017] [Medline: 24486562]

65. Jensen K, Soguero-Ruiz C, Oyvind MK, Lindsetmo R, Kouskoumvekaki I, Girolami M, et al. Analysis of free text in electronic health records for identification of cancer patient trajectories. Sci Rep 2017 Dec 07;7:46226 [FREE Full text] [doi: 10.1038/srep46226] [Medline: 28387314]

66. Carrell DS, Halgrim S, Tran D, Buist DSM, Chubak J, Chapman WW, et al. Using natural language processing to improve efficiency of manual chart abstraction in research: the case of breast cancer recurrence. Am J Epidemiol 2014 Mar 15;179(6):749-758 [FREE Full text] [doi: 10.1093/aje/kwt441] [Medline: 24488511]

67. Napolitano G, Marshall A, Hamilton P, Gavin AT. Machine learning classification of surgical pathology reports and chunk recognition for information extraction noise reduction. Artif Intell Med 2016 Dec;70:77-83. [doi:

10.1016/j.artmed.2016.06.001] [Medline: 27431038]

68. Warner JL, Levy MA, Neuss MN, Warner JL, Levy MA, Neuss MN. ReCAP: feasibility and accuracy of extracting cancer stage information from narrative electronic health record data. J Oncol Pract 2016 Feb;12(2):157-169. [doi: 10.1200/JOP.2015.004622] [Medline: 26306621]

69. Zopf JJ, Langer JM, Boonn WW, Kim W, Zafar HM. Development of automated detection of radiology reports citing adrenal findings. J Digit Imaging 2012 Feb;25(1):43-49 [FREE Full text] [doi: 10.1007/s10278-011-9425-7] [Medline: 22042494]

70. Ou Y, Patrick J. Automatic structured reporting from narrative cancer pathology reports. 2014 Presented at: HIKM '14 Proceedings of the Seventh Australasian Workshop on Health Informatics and Knowledge Management; 2014; Auckland.

71. Ou Y, Patrick J. Automatic negation detection in narrative pathology reports. Artif Intell Med 2015 May;64(1):41-50 [FREE Full text] [doi: 10.1016/j.artmed.2015.03.001] [Medline: 25990897]

72. Luo Y, Sohani AR, Hochberg EP, Szolovits P. Automatic lymphoma classification with sentence subgraph mining from pathology reports. J Am Med Inform Assoc 2014;21(5):824-832 [FREE Full text] [doi: 10.1136/amiajnl-2013-002443] [Medline: 24431333]

73. Ashish N, Dahm L, Boicey C. University of California, Irvine-Pathology Extraction Pipeline: the pathology extraction pipeline for information extraction from pathology reports. Health Informatics J 2014 Dec;20(4):288-305. [doi: 10.1177/1460458213494032] [Medline: 25155030]

74. Jouhet V, Defossez G, Burgun A, Le Beux P, Levillain P, Ingrand P, et al. Automated classification of free-text pathology reports for registration of incident cases of cancer. Methods Inf Med 2012;51(3):242-251. [doi: 10.3414/ME11-01-0005] [Medline: 21792466]

75. Afzal M, Hussain M, Khan WA, Ali T, Jamshed A, Lee S. Smart extraction and analysis system for clinical research. Telemed J E Health 2017 Dec;23(5):404-420. [doi: 10.1089/tmj.2016.0157] [Medline: 27782787]

76. Miller T, Dligach D, Bethard S, Lin C, Savova G. Towards generalizable entity-centric clinical coreference resolution. J Biomed Inform 2017 Dec;69:251-258 [FREE Full text] [doi: 10.1016/j.jbi.2017.04.015] [Medline: 28438706]

77. Mykowiecka A, Marciniak M, Kupść A. Rule-based information extraction from patients' clinical data. J Biomed Inform 2009 Oct;42(5):923-936 [FREE Full text] [doi: 10.1016/j.jbi.2009.07.007] [Medline: 19646551]

78. Bozkurt S, Lipson JA, Senol U, Rubin DL. Automatic abstraction of imaging observations with their characteristics from mammography reports. J Am Med Inform Assoc 2015 Apr;22(e1):e81-e92. [doi: 10.1136/amiajnl-2014-003009] [Medline: 25352567]

79. Denny JC, Choma NN, Peterson JF, Miller RA, Bastarache L, Li M, et al. Natural language processing improves identification of colorectal cancer testing in the electronic medical record. Med Decis Making 2012;32(1):188-197. [doi: 10.1177/0272989X11400418] [Medline: 21393557]

80. Denny JC, Peterson JF, Choma NN, Xu H, Miller RA, Bastarache L, et al. Extracting timing and status descriptors for colonoscopy testing from electronic medical records. J Am Med Inform Assoc 2010;17(4):383-388 [FREE Full text] [doi: 10.1136/jamia.2010.004804] [Medline: 20595304]

81. Thomas AA, Zheng C, Jung H, Chang A, Kim B, Gelfond J, et al. Extracting data from electronic medical records: validation of a natural language processing program to assess prostate biopsy results. World J Urol 2014 Feb;32(1):99-103. [doi: 10.1007/s00345-013-1040-4] [Medline: 23417341]

82. Ping X, Tseng Y, Chung Y, Wu Y, Hsu C, Yang P, et al. Information extraction for tracking liver cancer patients' statuses: from mixture of clinical narrative report types. Telemed J E Health 2013 Sep;19(9):704-710. [doi: 10.1089/tmj.2012.0241] [Medline: 23869395] 
83. Al-Haddad MA, Friedlin J, Kesterson J, Waters JA, Aguilar-Saavedra JR, Schmidt CM. Natural language processing for the development of a clinical registry: a validation study in intraductal papillary mucinous neoplasms. HPB (Oxford) 2010 Dec;12(10):688-695 [FREE Full text] [doi: 10.1111/j.1477-2574.2010.00235.x] [Medline: 21083794]

84. Garcelon N, Neuraz A, Benoit V, Salomon R, Burgun A. Improving a full-text search engine: the importance of negation detection and family history context to identify cases in a biomedical data warehouse. J Am Med Inform Assoc 2017 May 01;24(3):607-613. [doi: 10.1093/jamia/ocw144] [Medline: 28339516]

85. Chang N, Dai H, Jonnagaddala J, Chen C, Tsai RT, Hsu W. A context-aware approach for progression tracking of medical concepts in electronic medical records. J Biomed Inform 2015 Dec;58 Suppl:S150-S157 [FREE Full text] [doi: 10.1016/j.jbi.2015.09.013] [Medline: 26432355]

86. Figueroa RL, Flores CA. Extracting information from electronic medical records to identify the obesity status of a patient based on comorbidities and bodyweight measures. J Med Syst 2016 Aug;40(8):191. [doi: 10.1007/s10916-016-0548-8] [Medline: 27402260]

87. Wright A, McCoy AB, Henkin S, Kale A, Sittig DF. Use of a support vector machine for categorizing free-text notes: assessment of accuracy across two institutions. J Am Med Inform Assoc 2013;20(5):887-890 [FREE Full text] [doi: 10.1136/amiajnl-2012-001576] [Medline: 23543111]

88. Mishra NK, Son RY, Arnzen JJ. Towards automatic diabetes case detection and ABCS protocol compliance assessment. Clin Med Res 2012 Aug;10(3):106-121 [FREE Full text] [doi: 10.3121/cmr.2012.1047] [Medline: 22634542]

89. Zheng L, Wang Y, Hao S, Shin AY, Jin B, Ngo AD, et al. Web-based real-time case finding for the population health management of patients with diabetes mellitus: a prospective validation of the natural language processing-based algorithm with statewide electronic medical records. JMIR Med Inform 2016 Nov 11;4(4):e37 [FREE Full text] [doi: 10.2196/medinform.6328] [Medline: 27836816]

90. Pakhomov SVS, Hanson PL, Bjornsen SS, Smith SA. Automatic classification of foot examination findings using clinical notes and machine learning. J Am Med Inform Assoc 2008 Mar;15(2):198-202 [FREE Full text] [doi: 10.1197/jamia.M2585] [Medline: 18096902]

91. Smith DH, Johnson ES, Russell A, Hazlehurst B, Muraki C, Nichols GA, et al. Lower visual acuity predicts worse utility values among patients with type 2 diabetes. Qual Life Res 2008 Dec;17(10):1277-1284. [doi: 10.1007/s11136-008-9399-1] [Medline: 18972222]

92. Wei W, Tao C, Jiang G, Chute CG. A high throughput semantic concept frequency based approach for patient identification: a case study using type 2 diabetes mellitus clinical notes. AMIA Annu Symp Proc 2010 Nov 13;2010:857-861 [FREE Full text] [Medline: $\underline{21347100]}$

93. Pakhomov S, Shah N, Hanson P, Balasubramaniam S, Smith SA, Smith SA. Automatic quality of life prediction using electronic medical records. AMIA Annu Symp Proc 2008 Nov 06:545-549 [FREE Full text] [Medline: 18998862]

94. Walsh JA, Shao Y, Leng J, He T, Teng C, Redd D, et al. Identifying axial spondyloarthritis in electronic medical records of US veterans. Arthritis Care Res (Hoboken) 2017 Dec;69(9):1414-1420 [FREE Full text] [doi: 10.1002/acr.23140] [Medline: 27813310]

95. Turner CA, Jacobs AD, Marques CK, Oates JC, Kamen DL, Anderson PE, et al. Word2Vec inversion and traditional text classifiers for phenotyping lupus. BMC Med Inform Decis Mak 2017 Aug 22;17(1):126 [FREE Full text] [doi: 10.1186/s12911-017-0518-1] [Medline: 28830409]

96. Carroll RJ, Thompson WK, Eyler AE, Mandelin AM, Cai T, Zink RM, et al. Portability of an algorithm to identify rheumatoid arthritis in electronic health records. J Am Med Inform Assoc 2012 Jun;19(e1):e162-e169 [FREE Full text] [doi: 10.1136/amiajnl-2011-000583] [Medline: 22374935]

97. Chen W, Huang Y, Boyle B, Lin S. The utility of including pathology reports in improving the computational identification of patients. J Pathol Inform 2016;7:46 [FREE Full text] [doi: 10.4103/2153-3539.194838] [Medline: 27994938]

98. Soguero-Ruiz C, Hindberg K, Rojo-Alvarez JL, Skrovseth SO, Godtliebsen F, Mortensen K, et al. Support vector feature selection for early detection of anastomosis leakage from bag-of-words in electronic health records. IEEE J Biomed Health Inform 2016 Dec;20(5):1404-1415. [doi: 10.1109/JBHI.2014.2361688] [Medline: 25312965]

99. Chang EK, Yu CY, Clarke R, Hackbarth A, Sanders T, Esrailian E, et al. Defining a patient population with cirrhosis: an automated algorithm with natural language processing. J Clin Gastroenterol 2016;50(10):889-894. [doi: 10.1097/MCG.0000000000000583] [Medline: 27348317]

100. Shi X, Hu Y, Zhang Y, Li W, Hao Y, Alelaiwi A, et al. Multiple disease risk assessment with uniform model based on medical clinical notes. IEEE Access 2016;4:7074-7083. [doi: 10.1109/access.2016.2614541]

101. Geraci J, Wilansky P, de Luca V, Roy A, Kennedy JL, Strauss J. Applying deep neural networks to unstructured text notes in electronic medical records for phenotyping youth depression. Evid Based Ment Health 2017 Jul 24;20(3):83-87 [FREE Full text] [doi: 10.1136/eb-2017-102688] [Medline: 28739578]

102. Roque F, Jensen P, Schmock H, Dalgaard M, Andreatta M, Hansen T, et al. Using electronic patient records to discover disease correlations and stratify patient cohorts. PLoS Comput Biol 2011 Aug;7(8):e1002141 [FREE Full text] [doi: 10.1371/journal.pcbi.1002141] [Medline: 21901084]

103. Ananda-Rajah MR, Martinez D, Slavin MA, Cavedon L, Dooley M, Cheng A, et al. Facilitating surveillance of pulmonary invasive mold diseases in patients with haematological malignancies by screening computed tomography reports using 
natural language processing. PLoS One 2014;9(9):e107797 [FREE Full text] [doi: 10.1371/journal.pone.0107797] [Medline: $\underline{25250675]}$

104. Baechle C, Agarwal A, Zhu X. Big data driven co-occurring evidence discovery in chronic obstructive pulmonary disease patients. J Big Data 2017 Apr 4;4(1). [doi: 10.1186/s40537-017-0067-6]

105. Gaskin GL, Pershing S, Cole TS, Shah NH. Predictive modeling of risk factors and complications of cataract surgery. Eur J Ophthalmol 2016 Jun 10;26(4):328-337 [FREE Full text] [doi: 10.5301/ejo.5000706] [Medline: 26692059]

106. Chase HS, Mitrani LR, Lu GG, Fulgieri DJ. Early recognition of multiple sclerosis using natural language processing of the electronic health record. BMC Med Inform Decis Mak 2017 Feb 28;17(1):24 [FREE Full text] [doi: 10.1186/s12911-017-0418-4] [Medline: 28241760]

107. Abhyankar S, Demner-Fushman D, Callaghan FM, McDonald CJ. Combining structured and unstructured data to identify a cohort of ICU patients who received dialysis. J Am Med Inform Assoc 2014;21(5):801-807 [FREE Full text] [doi: 10.1136/amiajnl-2013-001915] [Medline: 24384230]

108. Pivovarov R, Elhadad N. A hybrid knowledge-based and data-driven approach to identifying semantically similar concepts. J Biomed Inform 2012 Jun;45(3):471-481 [FREE Full text] [doi: 10.1016/j.jbi.2012.01.002] [Medline: 22289420]

109. Cronin R, Fabbri D, Denny J, Rosenbloom S, Jackson G. A comparison of rule-based and machine learning approaches for classifying patient portal messages. Int J Med Inform 2017 Dec;105:110-120 [FREE Full text] [doi: 10.1016/j.ijmedinf.2017.06.004] [Medline: 28750904]

110. Ni Y, Wright J, Perentesis J, Lingren T, Deleger L, Kaiser M, et al. Increasing the efficiency of trial-patient matching: automated clinical trial eligibility pre-screening for pediatric oncology patients. BMC Med Inform Decis Mak 2015 Apr 14;15:28 [FREE Full text] [doi: 10.1186/s12911-015-0149-3] [Medline: 25881112]

111. Small AM, Kiss DH, Zlatsin Y, Birtwell DL, Williams H, Guerraty MA, et al. Text mining applied to electronic cardiovascular procedure reports to identify patients with trileaflet aortic stenosis and coronary artery disease. J Biomed Inform 2017 Dec;72:77-84 [FREE Full text] [doi: 10.1016/j.jbi.2017.06.016] [Medline: 28624641]

112. Zhou L, Lu Y, Vitale CJ, Mar PL, Chang F, Dhopeshwarkar N, et al. Representation of information about family relatives as structured data in electronic health records. Appl Clin Inform 2014;5(2):349-367 [FREE Full text] [doi: 10.4338/ACI-2013-10-RA-0080] [Medline: 25024754]

113. Chapman BE, Lee S, Kang HP, Chapman WW. Document-level classification of CT pulmonary angiography reports based on an extension of the ConText algorithm. J Biomed Inform 2011 Oct;44(5):728-737 [FREE Full text] [doi: 10.1016/j.jbi.2011.03.011] [Medline: 21459155]

114. Lin FP, Pokorny A, Teng C, Epstein RJ. TEPAPA: a novel in silico feature learning pipeline for mining prognostic and associative factors from text-based electronic medical records. Sci Rep 2017 Jul 31;7(1):6918 [FREE Full text] [doi: 10.1038/s41598-017-07111-0] [Medline: 28761061]

115. Nath, Albaghdadi MS, Jonnalagadda SR. A natural language processing tool for large-scale data extraction from echocardiography reports. PLoS One 2016;11(4):e0153749 [FREE Full text] [doi: 10.1371/journal.pone.0153749] [Medline: 27124000]

116. Alnazzawi N, Thompson P, Ananiadou S. Mapping phenotypic information in heterogeneous textual sources to a domain-specific terminological resource. PLoS One 2016;11(9):e0162287 [FREE Full text] [doi: 10.1371/journal.pone.0162287] [Medline: 27643689]

117. Kreimeyer K, Foster M, Pandey A, Arya N, Halford G, Jones SF, et al. Natural language processing systems for capturing and standardizing unstructured clinical information: a systematic review. J Biomed Inform 2017 Dec;73:14-29 [FREE Full text] [doi: 10.1016/j.jbi.2017.07.012] [Medline: 28729030]

118. Abbe A, Grouin C, Zweigenbaum P, Falissard B. Text mining applications in psychiatry: a systematic literature review. Int J Methods Psychiatr Res 2016 Dec;25(2):86-100. [doi: 10.1002/mpr.1481] [Medline: 26184780]

119. Spasić I, Livsey J, Keane JA, Nenadić G. Text mining of cancer-related information: review of current status and future directions. Int J Med Inform 2014 Sep;83(9):605-623 [FREE Full text] [doi: 10.1016/j.ijmedinf.2014.06.009] [Medline: 25008281]

120. Pons E, Braun LMM, Hunink MGM, Kors JA. Natural language processing in radiology: a systematic review. Radiology 2016 May;279(2):329-343. [doi: 10.1148/radiol.16142770] [Medline: 27089187]

121. Ching T, Himmelstein DS, Beaulieu-Jones BK, Kalinin AA, Do BT, Way GP, et al. Opportunities and obstacles for deep learning in biology and medicine. J R Soc Interface 2018 Apr;15(141) [FREE Full text] [doi: 10.1098/rsif.2017.0387] [Medline: 29618526]

122. Chiticariu L, Li Y, Reiss F. Rule-based information extraction is dead! Long live rule-based information extraction systems!. 2013 Presented at: Proc Conf Empir Methods Nat Lang Process EMNLP; 2013; Seattle.

123. Barnett GO, Cimino JJ, Hupp JA, Hoffer EP. DXplain. An evolving diagnostic decision-support system. JAMA 1987 Jul 03;258(1):67-74. [Medline: 3295316]

\author{
Abbreviations \\ BI-RADS: Breast Imaging-Reporting and Data System
}


CHF: congestive heart failure

CRF: conditional random field

DeepPhe: Cancer Deep Phenotype Extraction

EHR: electronic health record

EMR: electronic medical record

HF: heart failure

i2b2: Informatics for Integrating Biology and the Bedside

ICD: International Classification of Diseases, 10th Revision

IE: information extraction

MIMIC II: Multiparameter Intelligent Monitoring in Intensive Care II

NLP: natural language processing

PAD: peripheral arterial disease

PRISMA: Preferred Reporting Items for Systematic Reviews and Meta-Analyses

SVM: support vector machine

THYME: Temporal Histories of Your Medical Event

Edited by G Eysenbach; submitted 17.09.18; peer-reviewed by C Shivade, M Torii; comments to author 07.01.19; revised version received 04.03.19; accepted 24.03.19; published 27.04.19

Please cite as:

Sheikhalishahi S, Miotto R, Dudley JT, Lavelli A, Rinaldi F, Osmani V

Natural Language Processing of Clinical Notes on Chronic Diseases: Systematic Review

JMIR Med Inform 2019;7(2):e12239

URL: http://medinform.jmir.org/2019/2/e12239/

doi: $10.2196 / 12239$

PMID: 31066697

(C) Seyedmostafa Sheikhalishahi, Riccardo Miotto, Joel T Dudley, Alberto Lavelli, Fabio Rinaldi, Venet Osmani. Originally published in JMIR Medical Informatics (http://medinform.jmir.org), 27.04.2019. This is an open-access article distributed under the terms of the Creative Commons Attribution License (https://creativecommons.org/licenses/by/4.0/), which permits unrestricted use, distribution, and reproduction in any medium, provided the original work, first published in JMIR Medical Informatics, is properly cited. The complete bibliographic information, a link to the original publication on http://medinform.jmir.org/, as well as this copyright and license information must be included. 